\title{
電解化学発光検出フローインジェクション法による シュウ酸の定量
}

\author{
内 倉 和 雄*
}

(1989 年 12 月 16 日受理)

シュウ酸 $(\mathrm{Ox})$-tris $\left(2,2^{\prime}\right.$-bipyridine $)$ ruthenium $(\mathrm{II}) \quad\left\{\mathrm{Ru}(\mathrm{bpy})_{3}{ }^{2+}\right\}$ 電解化学発光系を利用した FIA 法を作成し，実試料への適用例として尿中シュウ酸の定量に応用した. キャリヤーに蒸留水を用いる 2 流路 FIA で，試薬溶液は $10 \mathrm{mM}$ 硫酸に $\mathrm{Ru}(\mathrm{bpy}){ }_{3} \mathrm{Cl}_{2}$ を溶解して $0.12 \mathrm{mM}$ とした。試薬溶液は電解 反応器 (electrochemical reactor, ECR) を通過した後, フローセルの直前でキャリヤーと合流し, 混合 した後，排出する。このとき生ずる光量を测定する. 本法によれば $0 \sim 400 \mathrm{pmol}$ の範用で発光強度と 良好な直線関係を示し, 検出下限 $(S / N=3)$ は $0.3 \mathrm{pmol}$ であった. 相対標準偏差 $(n=5,5 \mathrm{pmol})$ は $2.3 \%$ であった．尿中の Ox は尿を $1 \%$ アセトニトリル溶液で 1000～2000 倍に希秎し, Sep-Pak C18 で前処理することによって定量できた。

\section{1 緒 言}

シュウ酸 $(\mathrm{Ox})$ は, 植物や動物など生物中に存在し 生理学, 農学のみならず分析化学などによって重要なも のと言われている1). 更に, 臨床医学の範囲では, 尿あ るいは血中の Ox の測定が疾病診断 ·治療の目的で要求 されている ${ }^{2)}$.これまで定量法としては, 結晶沈殿 法 $^{1)}$, 同位体希釈法 ${ }^{3)}$, 酵素法 ${ }^{4}$, 修飾した電極を利用し たもの ${ }^{5)}$ やクロマトグラフィーを利用した方法 ${ }^{6)-9)}$, などが報告されている，これらは, 繁雑な処理が必要で あること, 分析時間が長いこと, 選択性及び感度など, 必ずしも十分でないと思われる. 最近, Bard ら 1011) は, $\mathrm{Ox}$ と $\mathrm{Ru}(\mathrm{bpy})_{3}{ }^{2+}$ を含む溶液を電解するときに 発光を観察し, 発光反応機構や $\mathrm{Ox}$ の分析への応用につ いて報告した。 しかし，実用分析法としては十分でない と思われるので, 流通系で連続的に電解することができ る電解反応器 (electrochemical reactor, ECR) を利用し た FIA による高感度・選択的で迅速な測定法を開発 し，尿試料に適用した。

\section{2 実験}

\section{$2 \cdot 1$ 試 薬}

$\mathrm{Ru}(\mathrm{bpy})_{3}{ }^{2+}$ 溶液: $10 \mathrm{mM}$ 硫酸に $\mathrm{Ru}(\mathrm{bpy})_{3} \mathrm{Cl}_{2}$ （Sigma）を溶かして $0.12 \mathrm{mM}$ とした. Ox 溶夜: シュ

\footnotetext{
*日本大学理工学部: 101 東京都千代田区神田駿河台
} $1-8$
ウ酸ナトリウム（標準試薬, 小宗化学薬品）を用時, 水 に溶解して用いた。そそ他の試楽はすべて市販特級品を 使用した。

\section{$2 \cdot 2$ 装置と操作法}

使用した FIA 装置を Fig. 1 に示す. ポンプは盛進製 薬 PSU-2.5Tを用いた。注入装置は Rheodyne 7125 に $10 \mu \mathrm{l}$ のサンプルループを付けて用いた．ECR は既報 ${ }^{12)}$ と同様のもので, 北斗電工ポテンショ・ガルバノスタッ トHA-101により加電される. 発光強度の測定は, 浜 松ホトニクスホトンカウンター G-1230 に光電子増倍管 R585を付けた. フローセルはシリコンチューブ（内径 $0.3 \mathrm{~mm}$, 長さ $140 \mathrm{~mm}$ ) を渦巻き状にして, アルミはく

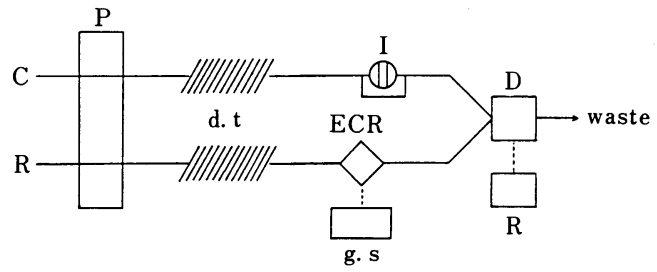

Fig. 1 Schematic flow diagrmam of FIA system $\mathrm{C}$ : carrier solution, flow rate $0.8 \mathrm{ml} \mathrm{min}^{-1} ; \mathrm{R}$ : reagent solution, flow rate $0.3 \mathrm{ml} \mathrm{min}^{-1} ; \mathrm{P}$ : pump; d. $\mathrm{t}$ : damper tubing, $0.5 \mathrm{~mm}$ i. d., $20 \mathrm{~m}$ length; I : injector, sample volume $10 \mu \mathrm{l}$; ECR : electrochemical reactor; g. s : potentio-galvanostat; $\mathbf{D}$ : detector; $\mathrm{R}$ : recorder 
の平面に固定したもので, 光電子増倍管の受光部に張り 付けて用いた。記録計は日本電子科学 U-228 で, FIA ピークを記録し，ピーク高さを測定し発光強度とした。

一方の流路は蒸留水をキャリヤーとして $0.8 \mathrm{ml}$ $\min ^{-1}$ で送液し, 他方は試薬溶液を $0.3 \mathrm{ml} \mathrm{min}{ }^{-1}$ で送 液した。試薬溶液は ECRに導かれ $80 \mu \mathrm{A}$ で定電流電解 を受け $\mathrm{Ru}(\mathrm{bpy})_{3}{ }^{2+}$ から $\mathrm{Ru}(\mathrm{bpy})_{3}{ }^{3+}$ に酸化される. 両溶液はフローセルの直前で合流し，七ル内で混合，流 出する. 試料は水に溶解し, その $10 \mu \mathrm{l}$ をキリヤー流 路に注入した。

\section{$2 \cdot 3$ 定量操作}

Sep-Pak C18 は水，アセトニトリル各 $5 \mathrm{ml}$ で洗净し た後, $1 \%$ アセトニトリル溶液を通過し, 平衡としたも のを用いた。

尿は 1\% アセトニトリルで 1000 2000 倍希积し， Sep-Pak C18 カラムに添加する. 流出液のはじめの 1.5 $\mathrm{ml}$ を捨て, 次の $0.5 \mathrm{ml}$ を集め, その $10 \mu \mathrm{l}$ を FIA に注 入する.

\section{3 結果と考察}

\section{$3 \cdot 1$ 検出条件の検討}

キャリヤー及び試薬溶液の流量をそれぞれ $0.8,0.3$ $\mathrm{ml} \min ^{-1}$ として, $\mathrm{Ru}(\mathrm{bpy})_{3}{ }^{2+}$ 濃度, $\mathrm{pH}$ 及び電解電 流の発光強度への影響について検討した。 $\mathrm{Ru}(\mathrm{bpy})_{3}{ }^{2+}$ 濃度が増加するにつれて, 発光強度は増大し, $0.1 \sim 0.24 \mathrm{mM}$ で一定となった（Fig. 2) ので, $0.12 \mathrm{mM}$ を採用した。次に, $\mathrm{pH}$ の影響について, 硫酸及び 10 $\mathrm{mM}$ リン酸緩衝液で試薬溶液を調製したものを用いて 調べた. $\mathrm{pH} 2 \sim 7$ と上昇するにつれて発光強度及びノイ ズ共に増大した. $S / N$ を考慮し $\mathrm{pH} 2.8$ を採用し, 硫酸 濃度を $10 \mathrm{mM}$ とした. 電解電流は $70 \sim 140 \mu \mathrm{A}$ の範囲

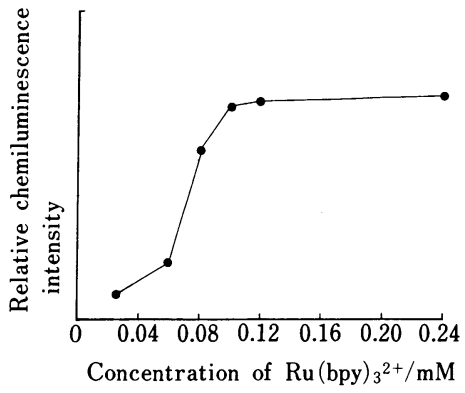

Fig. 2 Effect of $\mathrm{Ru}(\mathrm{bpy})_{3}{ }^{2+}$ concentration in the reagent solution on the relative chemiluminescence intensity
で調べた，電流を増加すると, 強度は増大した。しか し，ノイズも同様に増大し， $S / N$ はほぼ一定であった ので, $80 \mu \mathrm{A}$ とした. 採用した条件では, ノイズは無視 できる程度であり, キャリヤ一溶液の流量 $0.7 \sim 1.1 \mathrm{ml}$ $\mathrm{min}^{-1}$ において, 発光強度はほぼ一定であった。

\section{$3 \cdot 2$ 検量線, 感度と精度}

$2 \cdot 2$ で示した条件で直線性について調べた。Ox 400 pmol までは絶対量とピーク高さとは原点を通る直線関 係が認められた. Ox 2 6 pmol での FIA ピーグ Fig. 3 に示す. 又, Ox $5 \mathrm{pmol}$ を用い繰り返し測定したとこ ろ, 相対標準偏差 $(n=5)$ は $2.3 \%$ と良好な再現性を 示し, 検出感度は $0.3 \mathrm{pmol}(S / N=3)$ であった。これ は，既報 ${ }^{11) 13)}$ に比べ，約 10 倍高感度である.

\section{$3 \cdot 3$ 選択性と共存物質の影䉕}

実試料への応用を目的として選択性について調べた結 果を Table 1 に示す. 有機酸, アミノ酸, 還元性物質及 び無機塩類などについてほとんど発光を認めない。一 方, 発光したものについても, シュウ酸のそれに比較し て $0.3 \%$ 以下の強度であった. その中でトリプトファン （Trp）は Ox の約 2 倍の強度で発光した. 一方, Noffsinger ${ }^{13)}$ は $\mathrm{pH} 4 \sim 6$ において脂肪族アミン類が発光 すると報告しているが，本実験条件である $\mathrm{pH} 2.8$ では Ox に比較して $0.1 \%$ 以下の発光強度であった. 又, Table 1 の物質について $1 \mu \mathrm{M}$ Ox に等モル共存させた 試料溶液を調製し, 共存の影響を調べた結果, アスコル ビン酸について妨害が認められ, 発光強度は $93 \%$ 减少 した. 本反応は $\mathrm{Ru}(\mathrm{bpy})_{3}{ }^{3+}$ と $\mathrm{Ox}$ との酸化還元反応

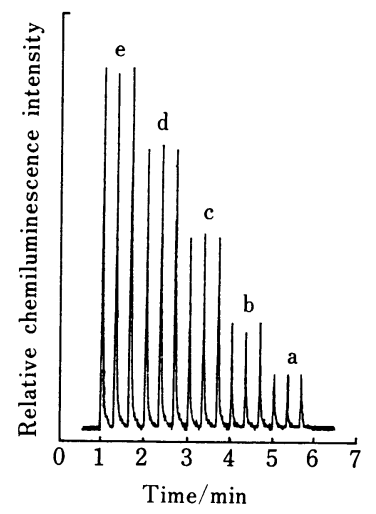

Fig. 3 Typical FIA peaks for the determination of oxalic acid

Oxalic acid (pmol) : a, 2; b, 4; c, 8; d, 12; e, 16 
Table 1 Relative chemiluminescence intensity of various compounds

\begin{tabular}{|c|c|}
\hline Compound & RGI \\
\hline Oxalic acid & 100.0 \\
\hline Formic acid & 0.0 \\
\hline Acetic acid & 0.0 \\
\hline Lactic acid & 0.0 \\
\hline Fumaric acid & 0.0 \\
\hline Tartaric acid & 0.0 \\
\hline Gitric acid & 0.0 \\
\hline Glycine & 0.0 \\
\hline Alanine (DL) & 0.2 \\
\hline Valine (DL) & 0.1 \\
\hline Leucine (DL) & 0.0 \\
\hline Threonine (DL) & 0.2 \\
\hline Aspartic acid (DL) & 0.0 \\
\hline Glutamic acid & 0.0 \\
\hline Lysine $(\mathrm{L})$ & 0.0 \\
\hline Arginine (DL) & 0.0 \\
\hline Phenylalanine (DL) & 0.0 \\
\hline Tryptophan (DL) & 198.0 \\
\hline Proline (L) & 0.0 \\
\hline Taurine & 0.0 \\
\hline Glucose & 0.0 \\
\hline Galactose & 0.3 \\
\hline Arabinose (L) & 0.1 \\
\hline Ribose (D) & 0.3 \\
\hline Ascorbic acid & 0.0 \\
\hline Glutathione, reduced & 0.0 \\
\hline Riboflavin & 0.0 \\
\hline Thiamine & 0.0 \\
\hline Hydrogen peroxide & 0.0 \\
\hline Perchloric acid & 0.0 \\
\hline Sodium chloride & 0.0 \\
\hline Potassium chloride & 0.0 \\
\hline Ferric chloride & 0.0 \\
\hline Zinc sulfate & 0.0 \\
\hline Manganese chloride & 0.0 \\
\hline Sodium bicarbonate & 0.0 \\
\hline Sodium metabisulfite & 0.0 \\
\hline Phosphoric acid & 0.0 \\
\hline
\end{tabular}

RCI : relative chemiluminescence intensity

によるものであり，アスコルビン酸が競争的に酸化を受 け, $\mathrm{Ru}(\mathrm{bpy})_{3}{ }^{3+}$ の濃度が減少したためと考えられる. 今回, 妨害を示さないグルタチオン（還元型）など, Ox に比較して易酸化性の物質は多量に共存するときに は妨害も予想される.

\section{$3 \cdot 4$ 実試料への応用}

応用例として尿中 $\mathrm{Ox}$ の定量を検討した. 本 FIA で

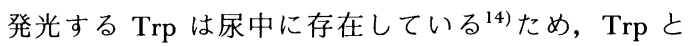
Ox の分離について, 試料液を前処理用ミニカラムに添
加し, Trp を吸着除去した後, その流出液を FIA に供 する方法を採用し，最適条件を調べた．Trp 及び Ox そ れぞれ $500 \mathrm{nM}$ を含む水及び水一アセトニトリル混液を Sep-Pak 7 種類及び Bond Elut SCX についてそれぞれ

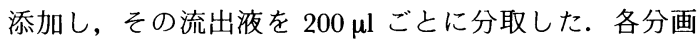
について発光強度を測定し, 破過曲線を作成した. 又, $\operatorname{Trp}$ 及び Ox 単独溶液についても調べた. Sep-Pak の silica, alumina, diol, -CN, florisil, accel- QMA 及び Bond Elut SCX については有効な分離が得られなかった。 Sep-Pak C18 の破過曲線を Fig. 4 に示す. 試料溶液を 水とすると, Trp は流出しないが, 流出液中の Ox 濃度 は試料液のそれに比較して低く, 一定值を示さなかっ

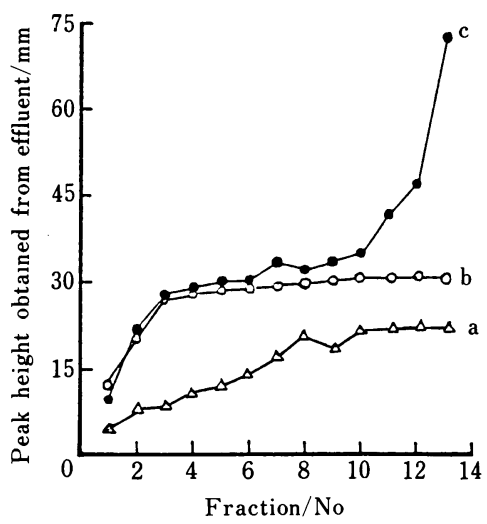

Fig. 4 Elution profiles for Ox and Trp from SepPak C18 cartridge column

Sample solution : a, $\mathrm{H}_{2} \mathrm{O}$; b, $1 \% \mathrm{CH}_{3} \mathrm{CN}$; c, 2 $\% \mathrm{CH}_{3} \mathrm{CN}$. Sample concentrations : $500 \mathrm{nM}$ Ox and Trp, respectively

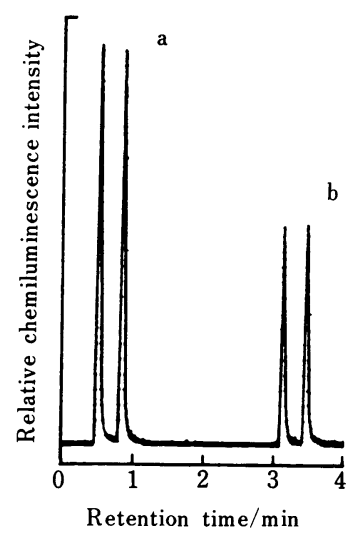

Fig. 5 FIA signals obtained from urine sample $\mathrm{a}$ : diluted urine; $\mathrm{b}$ : treated with $\mathrm{C} 18$ cartridge column 
Table 2 Determination of oxalic acid in urine and its recoveries

\begin{tabular}{|c|c|c|c|}
\hline \multirow[b]{2}{*}{ Sample } & \multicolumn{2}{|c|}{ Oxalic acid/mg l $\mathrm{l}^{-1}$} & \multirow[b]{2}{*}{ Recovery $^{\mathrm{b})}, \%$} \\
\hline & Urine & $\begin{array}{l}\text { Urine }+ \\
\text { standard }^{\text {a) }}\end{array}$ & \\
\hline 1 & 32.0 & 70.5 & $98.7 \pm 2.4$ \\
\hline 2 & 28.3 & 68.5 & $103.0 \pm 2.2$ \\
\hline 3 & 26.2 & 65.8 & $101.5 \pm 2.8$ \\
\hline 4 & 41.8 & 83.1 & $105.9 \pm 2.2$ \\
\hline 5 & 19.5 & 60.2 & $104.3 \pm 3.0$ \\
\hline 6 & 30.1 & 69.9 & $102.1 \pm 2.9$ \\
\hline 7 & 37.4 & 75.1 & $96.7 \pm 1.5$ \\
\hline 8 & 20.0 & 61.2 & $105.6 \pm 2.5$ \\
\hline
\end{tabular}

a) Oxalic acid was added to urine $\left(39.0 \mathrm{mg} \mathrm{l}^{-1}\right)$; b) Mean \pm S.D., $n=5$.

た. $2 \%$ アセトニトリルのときは, 12 分画から $\operatorname{Trp}$ の 流出が見られ, 定常部も短くなった。 アセトニトリルを $1 \%$ とすると 3 14 分画で一定濃度を示し $\operatorname{Trp}$ は流出 しない.このときの Ox の濃度は試料液の $93 \%$ であっ た. 以上の結果と尿中 $\mathrm{Ox}$ 濃度とから $2 \cdot 3$ を採用し た。尿についての FIA ピークの一例を Fig. 5 の b に示 す． a は希釈した尿を直接 FIA に注入したものであ る. 一時尿について $2 \cdot 3$ に従って測定した結果及び添 加回収率を Table 2 に示す．回収率は 97〜 105\% と良 好で，再現性も良く，共存物質による影響は無視できる ものと考えられる. 又, 测定した $\mathrm{Ox}$ 濃度は健常人の数 值 ${ }^{6) 15)}$ とよく一致した.

以上, 電解化学発光検出法を用いた FIA による Ox の選択的で高感度・迅速な測定法が確立できた。本法は 操作性に優れ，日常分析にも利用可能と思われる. 更 に，別法との比較などによって，より信頼度の高い方法 になると考えられる. 又, HPLC のポストカラム検出 法に応用することも可能と思われる.

\section{文献}

1) A. Hodgkinson: "Oxalic Acid in Biology and Medicine" (1977), (Academic Press, New York).

2) W. G. Robertson and M. Peacock: Nephron, 26, 105 (1980).

3) A. I. Vogel: "Textbook of Quantitative Inorganic Analysis", pp. 243, 320, 577 (1962), (Longmans, London).

4) A. R. Hilary, N. M. Kennedy, S. M. Kulwant I. M. Alasdair : Clin. Chim. Acta, 182, 247 (1989).

5) A. N. R. Mohammad, G. G. George, G. O. Neto :
Anal. Chem., 58, 523 (1986).

6) S. Imaoka, Y. Funae, Y. Sugimoto, N. Hayahara, M. Maekawa : Anal. Biochem., 128, 459 (1983).

7) R. P. Singh, G. H. Nancollas: Anal. Lett., 19, 1487 (1986).

8) M. S. Leonel, P. B. Richard: J. Chromatogr., 414, 161 (1987).

9) H. A. Moye, M. H. Malagodi, D. H. Clarke, C. J. Miles : Clin. Chim. Acta, 114, 173 (1981).

10) I. Rubinstein, A. J. Bard : J. Am. Chem. Soc., 103, 512 (1981).

11) I. Rubinstein, R. M. Charles, A. J. Bard: Anal. Chem., 55, 1580 (1983).

12）百瀬明子, 内倉和雄, 椛沢洋三: 分析化学, 32, 142 (1983).

13) J. B. Noffsinger, N. D. Danielson :. Anal. Chem., 59, 865 (1987)

14）日本生化学会: “生化学データブック”, p. 1602 (1980)，(東京化学同人).

15) R. K. Kobos, T. A. Ramsey: Anal. Chim. Acta, 121, $111(1980)$

赵

Determination of oxalate by FIA with electrogenerated chemiluminescence detection. Kazuo Uchikura (Department of Pharmacy, College of Science \& Technology, Nihon University, 1-8, Kandasurugadai, Chiyoda-ku, Tokyo 101)

A selective and sensitive method for the determination of oxalic acid using the electrogenerated chemiluminescence (CL) system, oxalate- $\mathrm{Ru}(\mathrm{bpy})_{3}{ }^{2+}$, was described Oxalate was reacted with $\mathrm{Ru}(\mathrm{bpy})_{3}{ }^{3+}$ continuously prepared from $\mathrm{Ru}(\mathrm{bpy})_{3}{ }^{3+}$ with an electrochemical reactor (EGR, home-made). The dual channel FIA apparatus was comprised of a delivery pump for both carrier and reagent solutions, a sample injector, damper tubing, the ECR and a photon counter. The oxidation potential of the working electrode in the ECR was maintained with a potentio-galvanostat. CL intensity was measured with a photon-counter which recorded FIA peaks graphically. The carrier solvent was $\mathrm{H}_{2} \mathrm{O}$ (flow rate, $0.3 \mathrm{ml} / \mathrm{min}^{-1}$ ) and reagent solution prepared in $10 \mathrm{mM} \mathrm{H}_{2} \mathrm{SO}_{4}$ to contain $0.12 \mathrm{mM} \mathrm{Ru}\left(\right.$ bpy) ${ }_{3} \mathrm{Cl}_{2}$ (flow rate, $0.8 \mathrm{ml} \mathrm{min}^{-1}$ ). The sample $(10 \mu \mathrm{l})$ was injected into the carrier stream. Linearity was obtained up to 16 pmol for oxalate. The detection limit was $0.3 \mathrm{pmol}(S / N=3)$. The relative standard deviation was $2.3 \% \quad(n=5,5 \mathrm{pmol})$. This method was successfully applied to the determination of oxalate in urine.

(Received December 16, 1989)

\section{Keyword phrases}

FIA; oxalate determination; chemiluminescence detection; tris(bipyridine)ruthenium complex; urine sample. 